Reprod. Nutr. Dévelop., 1988, 28 (1), 89-90.

\title{
Digestibilité du feuillage de chêne vert (Quercus ilex) distribué frais à des caprins entraînés au pâturage sur parcours (1)
}

\section{MEURET}

Unité d'Ecodéveloppement, I.N.R.A. -SAD

84140 Montfavet, France.

Summary. A high and steady intake of fresh branches of holm oak, distributed to local goats ( 28 days in April) led to a $100 \mathrm{~g} /$ day gain and a positive nitrogen balance despite low fiber digestibility. Our foraging conditions gave reliable results with very little variation between animals.

La mesure du comportement alimentaire de troupeaux caprins dans des taillis de chêne vert du Gard, montre que le feuillage de chêne représente plus de $60 \%$ de la matière sèche (MS) ingérée (Meuret et al., 1986). La présente étude précise la faisabilité d'une mesure de digestibilité du feuillage de chêne avec des caprins rustiques affouragés en rameaux.

Matériel et méthodes. Six chèvres taries de type génétique Rove, âgées de 2 ans, pesant $25 \mathrm{~kg}$ et élevées sur des parcours où elles consommaient du chêne vert, ont été placées en avril dans des cages à digestibilité spacieuses. Une structure métallique ajustable, dans laquelle 6 rameaux feuillés sont simultanément pincés, est montée devant chaque cage. Les rameaux opposent une résistance élastique au broutement qui conduit les animaux à adopter un comportement d'ingestion semblable à celui observé sur le parcours. La quantité ingérée est déterminée individuellement par pesée de chaque rameau avant et après broutement. La mesure de la teneur en MS du feuillage est corrigée en cas d'évaporation en cours de distribution (lot de rameaux témoins). La composition morphologique de l'ingéré est déterminée par classement de chaque rameau parmi 6 classes de types morphologiques des feuilles et parmi 4 classes d'abroutement de la matière consommable (feuilles et rameaux de premier et second ordre). Une reconstitution manuelle sur des lots de 20 rameaux représentatifs de chacun des types morphologiques et de chaque taux d'abroutement permet de définir la composition individuelle de l'ingéré, en termes de proportion des organes végétaux. La distribution des rameaux (récoltés au plus $2 \mathrm{~h}$ auparavant) a lieu continuellement de $10 \mathrm{~h} 30$ à $19 \mathrm{~h}$. La durée de consommation partielle ou totale d'un rameau varie de 2 à $10 \mathrm{~min}$. Un supplément de $0,81 \mathrm{~g} \mathrm{MS} / \mathrm{kg}$ PV.75 de tourteau de soja est distribué chaque soir, afin de représenter l'apport protéique des espèces herbacées du parcours. L'eau et un mélange minéral contenant des oligoéléments sont distribués deux fois par jour.

(') Etude réalisée avec l'aide du Conseil Régional Provence-Alpes-Côte d'Azur. 
Des échantillons de chaque organe végétal consommé sont prélevés à intervalle de 15 jours en vue de la détermination, par reconstitution, de la composition chimique des rations individuelles. Les animaux sont pesés à jeun tous les 3 jours. L'essai comprend 11 jours de période préliminaire d'accoutumance à la cage, avec mesure de l'ingéré, et 18 jours de récolte totale des fèces et des urines.

Résultats et discussion. La matière sèche ingérée est constituée de $86 \%$ de feuilles et contient $96,3 \%$ de matière organique (MO), 8,3\% de matières azotées (MA) et $30,5 \%$ de cellulose brute. La quantité de feuillage ingérée est élevée et stable pour les 6 animaux considérés durant 18 jours (tabl. 1 : CV $=4 \%$ ). La digestibilité de la MO varie peu d'une chèvre à l'autre $(49,1 \pm 1,0 \%)$ et correspond à celle d'un foin de graminées récolté tardivement. La digestibilité des fibres est médiocre mais celle des matières azotées est nettement meilleure que celle obtenue avec des caprins consommant du feuillage de chêne vert séché et compacté (MAT $=7,8 \%$, DMA $=35,9 \%$ : Guerrero et Boza, 1983). Une ingestion ad libitum couvre bien les besoins d'entretien et de fin de croissance des animaux, tant au niveau énergétique qu'azoté. Le gain de poids vif est régulier et le bilan azoté est positif.

TABL. 1. - Quantités offertes et consommées et digestibilité du feuillage de chêne vert et bilan azoté (18 jours en avril).

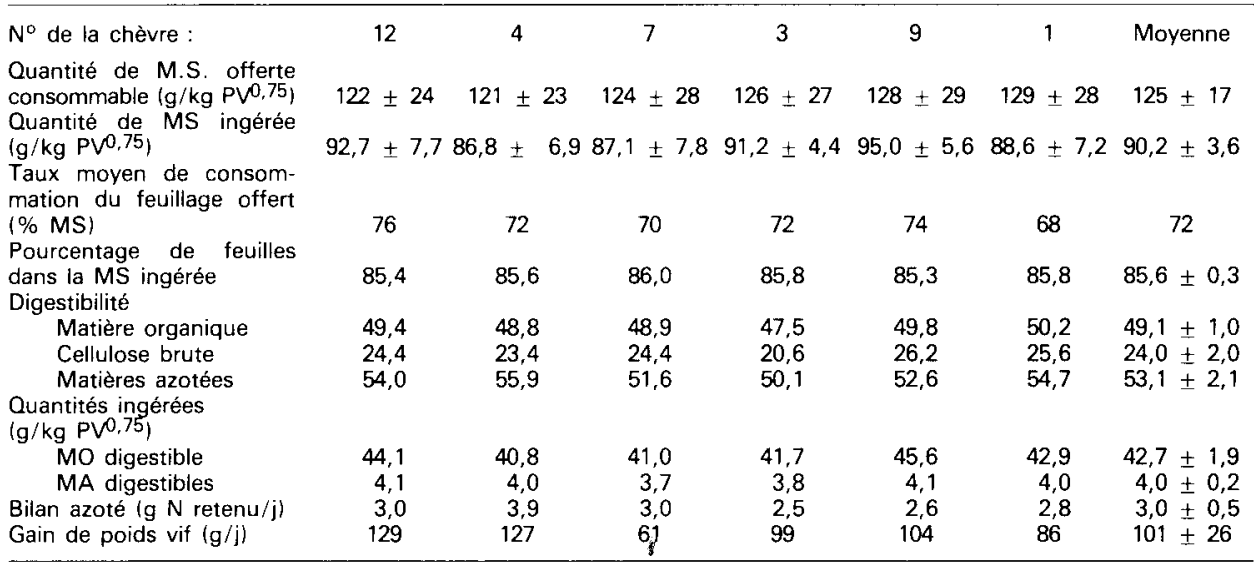

En reproduisant dans des cages confortables, les conditions de broutement sur parcours d'animaux habitués au fourrage, nous obtenons des résultats réguliers et fiables avec de très faibles variations entre les individus. Grâce à une ingestion élevée, le feuillage de chêne vert en avril couvre bien les besoins de caprins rustiques à l'entretien, malgré la faible digestibilité de sa matière organique. 